\title{
Problems and Countermeasures of rural left behind children in the context of urbanization in China
}

\author{
Lin Ling ${ }^{1,2, a}$ \\ 1. School of Marxism Education \\ University of Electronic Science and Technology \\ 2006 Xiyuan Boulevard,Chengdu, Sichuan , 611731, China \\ 2.Land and Resources College, \\ China West Normal University, \\ 1 Shida Rd,Nanchong ,Sichuan , 637009, China \\ aE-mail:15832562@qq.com
}

\begin{abstract}
Keywords: Left behind children; household registration system; educational consciousness; mental health; compulsory education

Abstract. The education of left behind children is a special social problem in the period of social transformation in China's rural areas, which has always been the concern of the community, Taking the rural left behind children in Jintang County of Sichuan Province as an example, this paper makes an empirical study on the present situation and the demand of the left behind children. The living conditions, learning education and mental health status of the left behind children were studied by the method of questionnaire survey and semi-structured interview. The main influencing factors of the living condition of the left behind children come from the national, social, school, family and the left behind children themselves and so on. The government, society, schools and families of left behind children should bear the corresponding responsibility to jointly supervise and solve the problems existing in the education of left behind children's growth, and strengthen the self education and guidance of the left behind children.
\end{abstract}

\section{The purpose and significance}

Early 1980s, with the accelerating process of China's reform and opening up, a large number of rural surplus labors freed from the land out, began to shift to the cities on a large scale. Army of migrant workers projections, not only to accelerate the modernization of China's urban construction process, but also greatly improved the economic landscape of the countryside, rural living standards improved significantly. However, at the same time restricted the urban-rural split dual social structure system, migrant workers continue to flock to the city to get rich, tens of millions of dollars to grow children of migrant workers has been affected to varying degrees. Migrant workers "Space urbanization" does not mean that the identity of the people, does not mean they can enjoy the same social rights and civil and public service, attached to the household registration system inequality, public services and social welfare as a shielding mechanism still plays the role of the identity of the segment. Children or wife problems mainly in enrollment opportunities, education route, to ensure funding, etc., subject to restrictions because of family economic capacity, social networks, urban social exclusion, such as multiple factors, most of the children of migrant workers cannot be treated urban life, only minor children will stay in the countryside, by the left-behind parent or guardianship by the grandparents to take care of or in trust for the long-term cannot live together create parent-child situation, which some children are called rural children left behind, left-behind children referred. According to the National Women's Federation in 2013 Task Force report, by the sixth census data estimated that there are $61,025,500$ children left behind in rural areas, accounting for 37.70 percent of rural children, accounting for 21.88 percent of the country's children[1]. And the fifth census estimate of 24.43 million as compared to the number of children left behind, [2] about ten years increased by 
1.5 times. Showing the number of children left behind in rural areas and more rapid growth, can be expected, in the journey of the national development of the new town, rural children left behind will continue to exist in the next longer period of time.

So many children away from their parents, they face a number of challenges in the growth process, the development of education, health and psychological aspects sparked widespread Worries. Moreover, the problem of children left behind with the current migration, urbanization, social integration and other issues are intertwined and influence to help the children left behind to deal with the challenges, you first need to unraveling the complex social problems from many angles and multi-level manpower recognize clear nature of the problem, explore countermeasures. This paper selects Sichuan Jintang County Guangxing town Jinbu kindergarten, Jinbu primary empirical research, Jintang is located northeast of Chengdu Plain, Jintang County registered a total population of 89.18 million, of which non-agricultural population of 22.89 million, of which agricultural population of about 66.29 million people, up to the proportion of $74.33 \%$, with a certain representation.

\section{Research Subjects and Methods}

\section{Definition of the concept of children left behind}

The phenomenon of children left behind through the ages is not unique to China, Japan Institute of Labor survey, in 1984 the national "single to his new post," the number of 14 million people in Japan, and there is an increasing trend.[3]The United Nations Children's fund, the United Nations development program and the South-South cooperation special agency (SU-SSC) research pointed out that about 1 million of Sri Lankan children stay at home. In Philippines, an estimated 8 million 800 thousand $\sim 900$ million children are separated from one or both of their parents.. In the Philippines, an estimated 8.8 million to 900 million children with one or both parents separated. In Moldova, one study estimated that children aged 0 to 14 years of age, $31 \%$ of one of the parents stay in the home, there are $5.4 \%$ both parents are left in the home. In 2002, nearly 13 percent of Mexicans and 22 percent of Salvadoran immigrants to the United States to live, and send their children to remain in their country of origin, [4]However, compared with other countries, China's rural children left behind in industrialization, urbanization a group process and flow of migrant workers under the background, although Europe has a large number of similar phenomenon population from rural to urban migration, but the long separation between parents and their minor children is not common. By the household registration system restrictions, the population of migrant workers in the urbanization process is different from the general sense of circulation and flow. In the process of the rural labor force into the city, not only to achieve geographical shift, career transition, but also to achieve identity transformation. In this particular model, China's urbanization is essentially semi-urbanization, migrant workers into the city has not actually Citizenship. Migrant workers and their children do not get the public identity, urban public schools for children of migrant workers did not fully open the door, and even children of migrant workers into the school must return to their places of origin or to participate in the college entrance exam. Under the influence of these factors, the current into the city with his parents' children of migrant workers accounted for only $20 \%$ to $30 \%$ of the total, and $70 \%$ to $80 \%$ of the children of migrant workers to stay in the home, to become left-behind children.[5]Thus, the barrier system to make our population movements in other countries showed a different course, and then rise to the rural left-behind children.

The term left-behind children in China first appeared in 1994, when refers to parents working abroad is learning to stay at home to look after the children have grandparents, after 10 years, the academic study of children left behind in this social group is almost zero in nearly a decade of silence, the academic study of children left behind rapid warming of the left-behind children by different researchers has defined the concept of academic but still lacks a clear definition and clear definition of this study in the adoption Ye Jingzhong "United Nations rights of the Child Convention "on the basis of the definition of the child, the children left behind is determined as follows: in rural areas due to 
both parents working outside or unilaterally long been unilaterally by the parents or elders, others for support, education and management of children (under the age of 18 years ) [6] The study object of this article is Jintang County town of Guangxing left-behind children in Jinbu kindergarten and Jinbu primary school.

(1) According to statistics provided by the school students in the school data,Jinbu kindergarten, Jinbu primary school children left behind in the progress of a total number of 872 students, including 716 children left behind, accounting for $82.11 \%$ the proportion of students, mostly children left behind and (outside) grandparents together the ratio of domestic (ie, inter-generational family structure) was $57 \%$, followed by the mother alone regulatory, accounting for $23 \%$, and much higher than the ratio of regulatory father alone $(7 \%)$. The survey shows that the proportion of children left behind in the boy's slightly higher than girls. More than half of children cannot be left behind either of the parents live together; they can only with grandparents (maternal grandparents) or other relatives living together. This situation, have an enormous impact on the character training of children left behind, and so will the psychological development.

(2) Consider the low age group of students of their limited capacity, only to survey the progress of the third grade and above grade 285 children. Each year the number of the basic situation is as follows: A third grade class, 87 people; a fourth grade class, 84 people; a fifth grade class, 77 people; two sixth grade classes, 73 people; a total of 321 people.

\section{Research Methods}

Combined with the survey research and field studies, December 2015, Jintang County Guangxing town Jinbu kindergarten, Jinbu elementary school teachers and students of the questionnaire survey and semi-structured access, also visited the part of the guardian. Surveys were conducted three times: once for the progress of students in the third grade above "the total number of children left behind and the type of family structure" survey, issued 285 questionnaires were returned of 285 , the recovery rate of $100 \%, 100 \%$ efficiency. The second was at first based on the children left behind from 285 randomly selected third grade children left behind more than fill out the "left-behind children questionnaire" form, issued 285 questionnaires were returned of 285, the recovery rate of $100 \%$ there was $100 \%$. The third is for the teacher respondents to "Questionnaire Survey of Children Left Behind" table, issued a questionnaire 8 parts, 8 recovery, the recovery rate of 100\%, 100\% efficiency. Meanwhile, children in kindergarten, low-grade children left behind daily living conditions, problems learning problems, emotional problems, mental health and ethical behavior and other aspects of visits, and from the community, schools, families and children left behind, and many made their own countermeasures.

\section{The findings}

\section{The children left behind the living conditions}

According to the survey, after the parents are out, no doubt, telephone, Internet and other universal rural children left behind and to promote exchanges between the parents go out, but the concern is that there are still $7 \%$ of children, parents feel unfamiliar with parents basically no communication. Parent-child interactions between parents and children left behind in the performance of long-distance space, short-term uncertainty and a non-face exchange on the way of practice, repetition and simple lack of emotional exchange on the content. Part grandparents guardian often grandchildren as apple, "inter-generational family" phenomenon is more prominent on the grandchildren love with Canada, while allowing more discipline, less criticism and education when children make mistakes, let alone punished, some also conducted shield, on the whole less effective discipline on children's behavior; and low part guardians of their own cultural quality, less ideological communication with children, education is relatively simple, rude, impatient and scientific methods in the education of children, scolding the child, beats a child's situation is more frequent; many grandparents guardian often feel tired, to poor monitoring children's behavior, not control, cannot control the situation when children have occurred. On the other hand, children left behind long 
separated from their parents, lack of a clear example of the image can imitate, combined with no parents in a timely manner to the pro-social behavior evaluation and reward strengthen pro-social behavior of children left behind difficult transition to a stable moral behavior. When they produce a strong inner conflict and confusion in understanding the complex moral situations when they face complex moral judgments difficult trade-offs in everyday life and social interaction, they urgently need a giver of moral knowledge, moral question problem, moral behavior are a model. The fact is, they are facing with their own have a serious "generation gap", the old concept of ancestors lack of knowledge on behalf of dependents, human moral example of moral deprivation causes normal learning process blocked, so that they cannot study in social ethics form the correct values and moral judgments [7]

Need to mention that the left-behind children generally have a strong self-care ability of children than their peers, they will cook, clean up the house, take care of younger siblings; In addition, part of the left-behind children also exhibit certain pro-social behavior, these prosaically behavior, and gradually won recognition of teachers and students to expand their social networks. The positive behavior of children left behind is actually a protective factor, this protective effect may include: economic conditions, social support from parents, school, peers and other aspects of children left behind their own positive coping these factors to some extent, alleviate the adverse effects of such parents are out of stressful life events on mental health.

\section{Mental Health of Children Left Behind}

Questionnaire analysis shows that in our interviews, the parents even met out seven or eight years have not seen a child contact cases. $85 \%$ of children say they want to stay in their parents live with them. Left-behind children of migrant workers and their parents to meet the frequency, select up to six months to one year, $29 \%$ of all children, at least another $45 \%$ of children met with their parents in the past six months. In other words, the vast majority of left-behind children and their parents to go out at least once a year of visibility. However, there is concern that there is still a considerable part of the children and their parents a long time no see. More than 2 years have not seen children left behind parents accounted for $7 \%$ of all children left behind - in the two years have not seen their parents accounted for $19 \%$. Survey results also show that, in the daily life difficulties left-behind children represent $26 \%$ of the first to own classmates or friends for help, 35 percent rely on themselves, $16 \%$ call my parents to find a solution, $17 \%$ teacher for help, Only $6 \%$ of children are willing to turn to their relatives for help. Through interviews, we found that differences in left-behind children a sense of security and non-left-behind children significantly younger when their parents separated, and the longer the separation time, the less time to spend in a year, the possibility of the child the greater the tendency to insecurity; emotional problems of children left behind mainly involves four areas: loneliness, grievances sad, sensitive, self-esteem and fears, where loneliness is the most left-behind children report emotional experience, the survey found that discrimination against children left behind perception was significantly higher than non-left-behind children, and there are no grades, gender differences in time and stay on, indicating that children left behind in the perception of discrimination is widespread. And parents who work are more likely to be seen as "No parents' children, so they may be more sensitive to discrimination against the outside world, the survey showed that there were significant differences separated from their parents at different times of the psychological situation of children left behind, separated from their parents time the longer, the lower the level of mental health of children left behind, various psychological problems are more prominent. Brothers and sisters living together with children left, their mental health situation is significantly better than no siblings and psychological problems of children left behind are mainly the child's parents are not as good as at home in interpersonal relationships and self-confidence, and in the loneliness, and social anxiety There was no significant difference in terms of learning to adapt with other children. Conclusion on the one hand exhibit ability to live independently children left behind, it also allows us to see a concern, children left behind in the rapid development of body and mind are in the primary period, their physical, mental, developmental and so many changes and facing troubles Since they are from their parents rarely have the opportunity to get the right education and guidance, 
leading them to prefer to get information from students, a friend, partner and peer understanding and awareness of life experience, to master the correct life knowledge, interpersonal communication other aspects are more naive, the lack of ability to judge things correctly or not, most children left behind some of their peers are more susceptible to bad habits, deviant behavior. Due to the long-term inter-generational or single-parent custody guardianship, custody and even others, unsupervised, so children can not be left behind as their parents care like other children, parents can keep abreast of, grasp the psychological, ideological changes in the child. This lack of family love to make the child become withdrawn, depressed, and even have a feeling of being abandoned.

\section{children left behind education situation}

With the development of society and new rural construction, education in rural children left behind are not as bad as previous described progress in kindergarten and primary schools where progress Jintang county under the jurisdiction of Chengdu, capital of Sichuan Province, in recent years, increasingly improved infrastructure, stage of basic education is guaranteed, but the fundamental problem is the problem of the quality of education, according to the survey, more than half of rural children left behind cannot be either of the parents live together, and the proportion is much higher than the flow out of father mother out of proportion, is particularly worth mentioning is that, due to limitations of the times, the vast majority of grandparents guardian educational level is generally low, even low levels of literacy; grandfather only read in primary school and no schooling ratio of $84.96 \%$, grandmother the ratio was $94.02 \%$, the average years of schooling grandparents were only 3.84 years and 3.16 years. Because of its limited level of education, their children learn custody is to continue to urge the children to complete the job on oral, as to whether it is by the quality of the job is completed, they cannot afford to judge. In other words, they learn the full supervision of the children to stay in form, only "routine" only. However, learning is an individual in the primary stage of adolescent developmental tasks, learning at this stage has a high utility value in our country; coupled, self-control poor primary school children, these grandparents when education of children left behind will face more challenges. Not only cannot effectively provide substantive course of study, due to its years of weak and feeble, left-behind children need to take up their time to help the family learn to take on more household chores and agricultural production, at the same time, many children left behind due to the still " under the influence of school dropout tide useless "and rural youth, lack of motivation to learn; in addition to individual Failing to compulsory education, rural children left behind have the opportunity to receive compulsory education, but the concern is that educational resources in rural areas is still scarce, although in local government support, primary progressive and progressive nursery hardware facilities gradually improved, rural schools in equipment, buildings and other aspects of the city and gradually narrow the gap, but because of the remote location, poor treatment of teachers, few teachers are willing to work, quality of teachers in terms of education level, the gap between teacher-student ratio, the proportion of teachers' promotion, access to training and other aspects of school opportunities remains significant progress in kindergarten is just a temporary recruitment of non-professional preschool teacher, teaching literacy-based content only, with 3 children 6-year-old main, simply cannot do age-minute teaching content, improve primary school teachers a total of 7, only one college graduate, is the year the remaining six are teachers or substitute teachers of private teachers to positive to positive, basically without professional training, removing a management staff, school teachers should bear a year per person, including language, mathematics, foreign language, and all courses are not even taught music, sports and other body art courses, mental health education is far behind, the presence of teachers the older, low professional quality, professional ability is not high, the quality of teaching can be imagined, this reflects the current plight of Chinese rural basic education.

\section{Discussion}

The household registration system of urban and rural segregation is the institutional reason of the problem of rural left behind children 
The establishment of China's household registration system was originally designed to prevent a large number of rural populations into the city blindly. Around 1956, due to reasons such as natural disasters, etc., a large number of farmers into the city looking for a chance to live, begging or flee from famine, the city caused great impact. Therefore, in 1956 December the State Council issued "the State Council on the prevention of the rural population of blind drain instructions", in March 1957, September and December and continuous issued a notice and instructions, called on all localities to take measures to stop the exodus of farmers. January 1958, the first session of the National People's Congress meeting, 91, officially announced the implementation of the "People's Republic of China Household Registration Ordinance". For a long time, the household registration system while maintaining social stability, control of urban population and coordination of the social resources allocation plays a certain positive role, but it also between the urban people (non farmers) and rural (agricultural households) set up a strict distinction. After the reform and opening up, the household registration system limit the flow of farmers began to fade, farmers can relatively free access to migrant workers in the city, but the household registration system still to farmer's identity, employment, education and living standards to limit. Although they enter the city from farmers, from farmers to migrant workers, but not into the public, their household registration of farmers has not changed, they cannot enjoy the benefits of urban residents. In the huge and bustling city, although they bear the city's bitter, tired, the dirtiest, most dangerous work, but they can only live in urban fringe simple rental housing, even in the construction site or simple work shed. Therefore, the hard working life, they cannot bring their children into the city, only to let the children stay at home.

\section{Family structure split, resulting in children left education is facing a series of challenges}

In 1966, Professor John Hopkins University, USA 4000 Coleman collected data 600,000 school children, wrote the "Report on the equality of educational opportunity" in the international community had a major impact. Report with a large number of data show that the main factor affecting the child's academic performance is the family.

Lack of family education affects the physical and mental development of children left behind, but from a macro point of view that the lack of family education of children left behind not only slowed the process of development of rural education, and is not conducive to further improve the average years of schooling of rural, urban and rural areas could easily lead to differentiation Social structure.[8] the root of the problem of rural children left behind from splitting and the absence of family education family structure. Despite the existence of studies in age categories of children left behind, left behind the time and care model, etc are some differences, but no matter how we define left-behind children, parent-child separation are undeniable - is that the group most essential and core features. For most rural households in China, the rural adult workers to stay at home if arable land barely subsistence, migrant workers are able to provide a steady flow of remittances to stay home; but after all migrant workers at the bottom of the labor market, due to the income low, poor living conditions, high cost of living in cities, some cities for the children of migrant workers exist barriers to education, the majority of migrant workers forced to choose between bringing up their children in the rural home of minor children will not be left in the home belonging to Pat selection by the grandparents take care of, Parental separation of families forced to become their decisions, while families of migrant workers and changes in the structure of relations, will inevitably produce a variety of left-behind children affected. The relationship between family structure and patterns of migrant workers and their children long-term parent-child separation, based both left-behind children and issues related to the formation, but also constitute the basic starting point for a series of studies of the left-behind children's issues. Although most left-behind children and their parents go out to a relatively stable telephone communication, but from the communication frequency and content point of view, there are still many problems.

\section{Family awareness education of children left behind weak}

Lack of family warmth make left-behind children had a great variation in personality, psychological, difficult for them to integrate into the normal peer group. Because their parents or guardians, grandparents own lack of cultural training, family education did not notice the influence of 
left-behind children. In a dialogue with the guardians of children left behind, there was a guardian says:. "Parents just child's food and clothing, education is the school teachers do, children to school, the school management, there is nothing we do not trust." This parents who speaks for a considerable part of the left-behind parents of children view. When they take care of children left behind, often thought to give a child to buy some clothes, settle tuition, living expenses and return, that is, care for children, only pay attention to whether the child tall, fat, and, ignoring the mental health and behavior the importance of the guide, long-term laissez-faire, condone child, resulting in distortion of personality psychology, behavioral deviations occur, even on the path of crime. In addition, the relationship between man other children left behind despite sympathy for them or regulatory obligation, but because of their own depth burden and kinship families varies helpless.

\section{Rural children left behind in all aspects of school education are facing challenges.}

Advances in kindergartens and primary schools progress, we deeply feel, is not up to the quality of the professional staff of teachers, children left behind education will bring a lot of trouble due to low treatment of teachers in rural areas, poor living conditions, the phenomenon of wage arrears for teachers is serious, a lot of people do not want to teach in rural areas. Some graduate students would rather stay at home waiting list, rather than to work in the countryside. At the same time, with the merit of teachers into the city, more and more outstanding teachers to the city. Because of the loss of teachers, a teacher in the middle and primary schools in poor rural areas is a common phenomenon. In many rural schools, teachers are badly short of the needs of the new curriculum reform. In addition, one of the important factors that cause the shortage of teachers in rural education is the one - way flow of teachers, that is, excellent teachers only have upward mobility. If the village teachers teach well, believing from entering the town school, town teacher if teach well, enter school of County town. And so on. This kind of rigid selection mechanism led to the rural basic education system can only get a poor source of teachers.

\section{The countermeasures and suggestions of children left behind education}

Many studies have already proven the existence of children left behind more prominent problems in mental health, social adaptation, and behavior norms. Most parents under conditions permitting their children to work or want to personally take care of reading, but to achieve this desire there are still many obstacles, such as: urban education resources are limited, school tuition is too high, the city's consumer price too expensive, parents too busy no time to care for their children, parents liquidity too most children of migrants left behind or to the identity of the child to remain in their places of origin.[9]Common school-age migrant children, school problems are far from eradication, human science, education process inequities evident, remote education and so on outstanding issues of convergence . [10]

\section{Government to strengthen legislation and concerns of children left behind}

First, it should be phased out household registration management system, improve identity management system; the establishment of integrated urban and rural household registration system, to facilitate migrant workers' children go to school locally. Government should formulate preferential policies to school children left behind in the city, along with school children's parents work outside the home, giving migrant workers and their children for the effective treatment of the public, the opportunity to let their children enjoy equal education. In addition, governments at all levels should update the concept, to increase the children left behind legislation to protect all kinds of problems. "National new urbanization plan (2014- 2020)," In reaffirming the mobile child compulsory education "two-oriented" policy at the same time, requirements "for school failure in public schools, to take government procurement of services, etc., with the protection of migrant workers move 'children rights "in the inclusive private school, which is an important measure to protect migrant children equal access to education. This highlights the country to solve the problem of migrant children's attention. However, objectively speaking, the relevant sectors, particularly in areas related to the implementation of these important guidelines and deployment in the understanding, there are 
still a big gap on the measures, a lot of time to solve the problem of education of migrant children who still prevaricating, watching delay attitudes and practices. These attitudes and practices inconsistent with the requirements of the party and state, but will not help solve the problem, the government should reform public official performance appraisal system, establish the concept of service-oriented government, take care of children left behind as to build a harmonious society and promoting the promotion of social an important part of new countryside construction; governments should formulate policies and welfare of children left behind to take legal means to implement security policies, the welfare of children left behind as part of social welfare, to provide them with cash, in-kind, social services and education and training help, in particular legislative solution children living in poor families of their lives, education, medical aspects of various security issues. Governments should also develop the welfare of children left behind; learn from other welfare organizations management, the establishment left behind child welfare agencies, so that left-behind children receive care and care of the whole society.

Promoting the development of rural urbanization process, the migrant workers locally to encourage the transfer of migrant workers return home business together.

There are many problems after urbanization, in the field of population flow is the most prominent manifestation of labor but no one saw urbanization, institutional arrangements often see only isolated individuals, but not for families and children. Urbanization development is conducive to the integration of urban and rural areas and urban-rural integration, help with the development of this small town to promote the development of the vast rural areas. Objectively speaking, to achieve the transfer of rural surplus labor force in place will reduce the generation of left-behind children fundamentally, but also the prosperity of rural development objective to contain the dynamic flow of migrant workers. In recent years, some areas are facing east land space, energy resources, population and environmental carrying capacity unsustainable burden issue, the further development of traditional manufacturing restricted. At the same time, under the influence of the current international financial crisis, the eastern part of upgrading the industrial structure of the problem is particularly urgent. Thus, the industrial upgrading of the eastern Midwest to shift the flow of migrant workers will have a significant impact, after 30 years of flow out after reflux entrepreneurial trend of migrant workers are increasingly apparent, at the same time, the global financial crisis under our employment situation is grim, a large number of unemployed migrant workers, increase employment difficulties, forcing a considerable part of migrant workers return home business. The Government should take this opportunity to actively guide these two trends, the Midwest industrial transfer to undertake to do work related to the county as the center to develop the county economy and the development of rational policies to encourage migrant workers to return home and locally to transfer entrepreneurship, reducing the number of rural children left behind

\section{To solve the problem of rural children left behind in the development of rural education background and premise}

Strengthening school education we must increase government investment in schools, the government should be reasonable with urban and rural educational resources. First, the state financial expenditure on education should be appropriate to rural areas for rural schools acquire the necessary modern hardware facilities, while preferential policies or economic subsidies in the form of high-quality education to attract people to join the ranks of the rural education; Second, the Government should be established in rural boarding schools, boarding schools can solve the left-behind children unattended, learning problems, and security can not be guaranteed, the lifting of rural migrant workers' worries. " To attract more rural children left behind and receive at the same time, can reduce the relative number of children flowing into the city, so as to reduce pressure on urban education.

Play rural community education, improve the rural children left behind in the social care system. Government has the responsibility for the healthy growth of children left behind to create a good community environment, social care system to improve the rural left-behind children; children left behind in rural schools to improve the regulatory system, schools should build students left their parents and guardians of personal archives. Courses for left-behind children's psychological education, 
to solve their psychological confusion on their proper guidance. While keeping teachers and students, "Mentor" intimacy, so that left-behind children, especially to make boarding students left feel the love from the school to organize class units or grades, full of humane care group activities (such as organized students to the left-behind children's birthday, organization of children left behind to join the party activities, etc.), and gathering strength left behind groups of children to enable them to more infection school family atmosphere

Changing the guardian heavy parenting, education light phenomenon, to help children left to establish a correct concept of family education, strengthen exchanges between parents and stay out of their children.

Family, school and society together to form the children's growth environment. In the left behind children in the family, parents should not only not in children around and prevarication, give up action, but also should actively take more action to compensate for the family split bring to their children because of injury. We should encourage parents and children live together as much as possible. Encourage parents to go to work in the conditions permit the children should be brought to school children to school, to create conditions for the healthy growth of children. You can not get the children around, from the point of view of the child to grow up, to find the best guardian of the child and the child's teacher to maintain regular communication. As much as possible to reduce the proportion of mothers of migrant workers, should encourage parents to gain time with their children as much as possible to communicate, walk into their hearts, try to meet the child to parents care and psychological needs. Go out for both parents to guide their children and strengthen contact, through communication and communication let left-behind children feel the warmth of family, the children play on the unique educational function of parents.

\section{Acknowledgements}

This work was financially supported by the Project of Education Department of Sichuan Province (CSZ12026), The subject of Ideological and political education in the Education Department of Sichuan Province (CJS12-064).

\section{Reference}

[1]Chinese women's movement. National rural children left behind, rural-urban migration study the situation of children. National Women's Task Force Vol.6 (2013),p.30-34

[2]Duan Rong., Yang Ke. Study of Rural Children Left Behind. Population Research, 3, 15-25

Xiaohua.(1996). "Single new post" and Japanese modern society. Foreign Studies Vol.4(2008),p.45

[3]Pan Lu., Ye Jingzhong. Rural Children Survey. China Agricultural University (Social Science Edition) Vol.7(2006),p.5-17

[4]Gu Shengzu. Road Research urbanization with Chinese characteristics. Chinese population • Resources and Environment Vol.1 (2009),p.67

[5]Xu Yongguang.in: Let the children of migrant workers into the city to have more opportunities to study. edtied by People's Daily,Beijing, NY (2009), in press.

[6]Ye Jingzhong., James Murray.:Children Left concern: China's western rural areas of migrant labor on children left behind(Social Sciences Academic Press,Beijing 2005).

[7]Chi Xixin. Psychosocial children left behind new ethical problems. Educational Research Vol.2(2005),p.29-32.

[8]Huang Xiaohui. Thoughts on Family Education missing children left behind in rural areas .Contemporary Education ForumVol.5(2006),p.19-21

[9]Kong Dehua., Cao Guangzhong. Flow or stay behind: children in school for rural migrants to choose and China to investigate factors.Chinese Rural Economy Vol.6 (2011),p.37-44.

[10]Research group Education Development Central. Education Employment farmers Compulsory Education for Children. Huazhong Normal University Chinese migrant workers.Vol.3(2013,p.11 
